\title{
Analysis of prescribing pattern of antihypertensive drugs during pregnancy and neonatal outcome in a tertiary care centre
}

\author{
Soundarya Yamakanamardi ${ }^{1 *}$, Anuradha $\mathrm{HV}^{1}$, Sujani BK${ }^{2}$, Shivamurthy $\mathrm{MC}^{1}$
}

${ }^{1}$ Department of Pharmacology,

${ }^{2}$ Department of Obstetrics and Gynaecology, M. S. Ramaiah Medical College and Hospital, Bengaluru, India, 560054

Received: 10 February 2016 Accepted: 14 March 2016

\section{*Correspondence to:}

Dr. Soundarya V.

Yamakanamardi,

Email: soundaryavy@gmail.com

Copyright: (C) the author(s), publisher and licensee Medip Academy. This is an openaccess article distributed under the terms of the Creative Commons Attribution NonCommercial License, which permits unrestricted noncommercial use, distribution, and reproduction in any medium, provided the original work is properly cited.

\begin{abstract}
Background: Hypertensive disorders are the most common medical complications of pregnancy with an incidence of 2-8\%. Maternal hypertension, even of the mild to moderate category, can lead to adverse perinatal outcomes like low birth weight, prematurity, stillbirth and intrauterine growth retardation. Though hypertension occurs up to $8 \%$ of pregnancies, yet information on the safety of antihypertensive medication use during pregnancy is limited. The objective of this study was to analyse the prescription pattern of antihypertensive drugs in pregnant woman and also to assess the neonatal outcome in pregnant woman on antihypertensive drugs.

Methods: The retrospective study includes analysis of all the prescriptions from case records of hypertensive pregnant women till the delivery for one year.

Results: Total number of 122 hypertensive pregnant patients was included in the study. Mean age of the patients was 25.8 years. $51.6 \%$ were primigravida. Most of them were diagnosed after $28 \pm 2$ weeks of pregnancy. $54 \%$ were on monotherapy. Most commonly used drug was alpha methyl dopa followed by nifedipine. Out of $86.9 \%(n=106)$ live birth delivered; $29.2 \%$ were of low birth weight.

Conclusions: All the prescriptions were prescribed rationally. Most of the prescriptions contain monotherapy with alpha methyl dopa which is considered to be safest antihypertensives in pregnancy.
\end{abstract}

Keywords: Antihypertensive drugs, Pregnancy, Neonatal outcome, Retrospective study

\section{INTRODUCTION}

Hypertensive disorders are the most common medical complications of pregnancy with an incidence of 2 to 8 $\%{ }^{1,2}$ It is one of the major causes of maternal and perinatal morbidity and mortality worldwide. There are several major categories of hypertensive disorders in pregnancy ranging from mild to moderate rise in blood pressure without proteinuria usually called pregnancy induced hypertension (PIH), preeclampsia (hypertension with proteinuria), severe preeclampsia and eclampsia. ${ }^{2}$ Maternal hypertension, even of the mild to moderate category, can lead to adverse perinatal outcomes like low birth weight, prematurity, stillbirth and intrauterine growth retardation. ${ }^{3}$ Though hypertension occurs in 2 to $8 \%$ of pregnancies, yet information on the safety of antihypertensive medication use during pregnancy is limited. For severe hypertension, anti-hypertensive medication is used to prevent serious maternal and foetal complications; however, there is no consensus on when to treat mild-to-moderate hypertension. According to ACOG (American college of gynaecology) technical bulletin recommends that drugs not to be administered in pregnancy associated with hypertension, if systolic BP is less than 160 and diastolic BP less than $110 .^{4}$

Hypertensive pregnant mothers are at increased risks for premature delivery, intrauterine foetal death, growth retardation and abruptio placentae; they also have an increased risk of vascular injury with thrombotic microangioplasty, coagulopathy, cerebral haemorrhage, and multi organ injury especially of kidney and liver. So as to avoid all such complications, it is better to start the treatment with antihypertensive after assessing correct stage and class of hypertension and always prescribe the safe drug to avoid adverse effects over the foetus and 
mother. The goal of antihypertensive therapy is to protect the mother from the extremes of hypertension and allowing the pregnancy to continue so that foetus to grow and mature normally. Teratogenic risks, potential adverse effects on foetal cardiovascular of end organ function and a potential impact on foetal growth and utero-placental hemodynamic and perfusion are also be observed to ensure the safety of the drug. ${ }^{5}$

Although treatment with medication might benefit the mother, it carries potential risks to the fetus from both impaired utero-placental perfusion and foetal exposure to the medications. ${ }^{6}$ Study of prescribing pattern is a component of medical audit which seeks monitoring, evaluation and necessary modifications in the prescribing practices of the prescribers to achieve rational and cost effective medical care. Thus, the monitoring of prescription and drug utilization studies can identify the problems and provide feedback to prescribers so as to create awareness about irrational. ${ }^{7}$ Objective of this study was to analyse the prescription pattern of antihypertensive drugs in pregnant woman and to assess the neonatal outcome in pregnant woman on antihypertensive drugs.

\section{METHODS}

This was a retrospective study which included analysis of all the prescriptions from case records of hypertensive pregnant women in a tertiary care hospital for a period of one year. Hypertension is defined and staged according to the guidelines of the seventh report of the Joint National committee on prevention, detection, evaluation, and treatment of high blood pressure. ${ }^{8}$ This study was undertaken after taking clearance from institutional ethics committee. Inclusion criteria for our study were pregnant woman with hypertension aged more than 18 years. The prescriptions were assessed on the basis of patient details including age, category of hypertension during pregnancy and drugs prescribed. Neonatal outcome was assessed with the category of hypertension during pregnancy. Total enumeration method of sampling was done to calculate the sample size.

\section{RESULTS}

In our study, total of 122 hypertensive pregnant patients were analysed. The mean age of the patients was 25.8 years; with a minimum age of 18 years and maximum 39 years. Among 122 hypertensive pregnant women, 52\% were primigravida whereas $6 \%$ multigravida (Figure 1). Among the Pregnant women associated with hypertension, 79 were diagnosed as pregnancy induced hypertension, 26 were preeclampsia and 13 patients were severe eclampsia (Table 1). When timing of diagnosis of hypertension was analysed, $95 \%$ of the patients were belong to gravida more than 28 weeks.
Table 1: Diagnosis of hypertensive pregnant women.

\begin{tabular}{|lc|}
\hline Diagnosis & \multicolumn{1}{|c|}{ No. of Patient N (\%) } \\
\hline Pregnancy induced hypertension & $79(64.75)$ \\
\hline Preeclampsia & $26(21.32)$ \\
\hline Severe Preeclampsia & $13(10.65)$ \\
\hline Eclampsia & $02(01.64)$ \\
\hline Chronic hypertensive & $02(01.64)$ \\
\hline
\end{tabular}

Table 2: Comorbid illness among hypertensive pregnant women.

\begin{tabular}{|lc|}
\hline Comorbid illness & $\begin{array}{c}\text { Number of patients } \\
\text { N=45 (35.2\%) }\end{array}$ \\
\hline Hypothyroidism & 21 \\
\hline Anaemia & 08 \\
\hline Gestational diabetes mellitus & 04 \\
\hline Anaemia+hypothyroidism & 02 \\
\hline Type 2 diabetes mellitus & 02 \\
\hline Acute pancreatitis & 02 \\
\hline Coronary heart disease & 01 \\
\hline Rheumatic heart disease & 01 \\
\hline Epilepsy & 01 \\
\hline Fibroid uterus & 01 \\
\hline Thrombocytopenia & 01 \\
\hline Chronic UTI & 01 \\
\hline
\end{tabular}

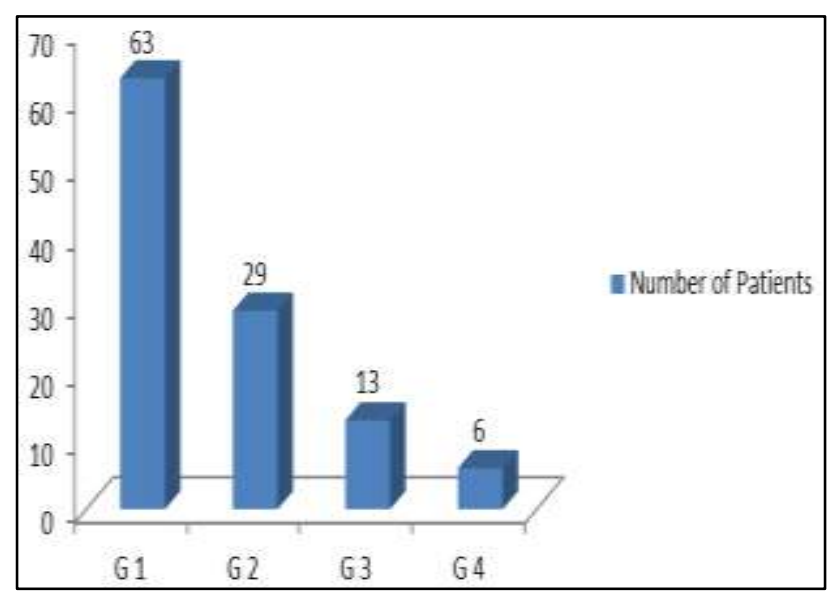

Figure 1: Gravida status of patients.

About $35.2 \%$ hypertensive pregnant women were having a comorbid illness. Most common comorbid illness found was hypothyroidism followed by anaemia and diabetes (Table 2). All women were on antihypertensive medication; monotherapy was used in $54 \%$ patients whereas polypharmacy in $46 \%$ (Figure 2).

Most commonly used antihypertensive was alpha methyl dopa followed by nifedipine and labetalol. Among polypharmacy, 45 patients were on combination of alpha methyl dopa and nifedipine (Figure 3).

On analysis of neonatal outcome, it was found that 106 $(86.9 \%)$ were live births followed by $14(11.5 \%)$ were 
born dead and $02(01.6 \%)$ were still born. Low birth weight was seen in 31 new born out of 106 live births.2out of 8 patients who were on atenolol gave birth to very low birth weight new-borns. APGAR score was between 7-10 in 92 live births; 4-6 in 11 and less than 3 in 3 live births.

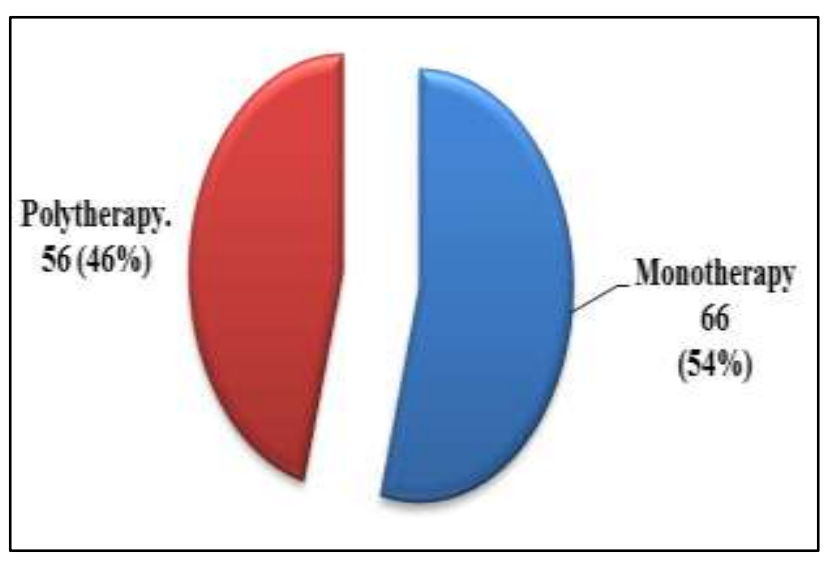

Figure 2: Antihypertensive agents used in hypertensive pregnant women.

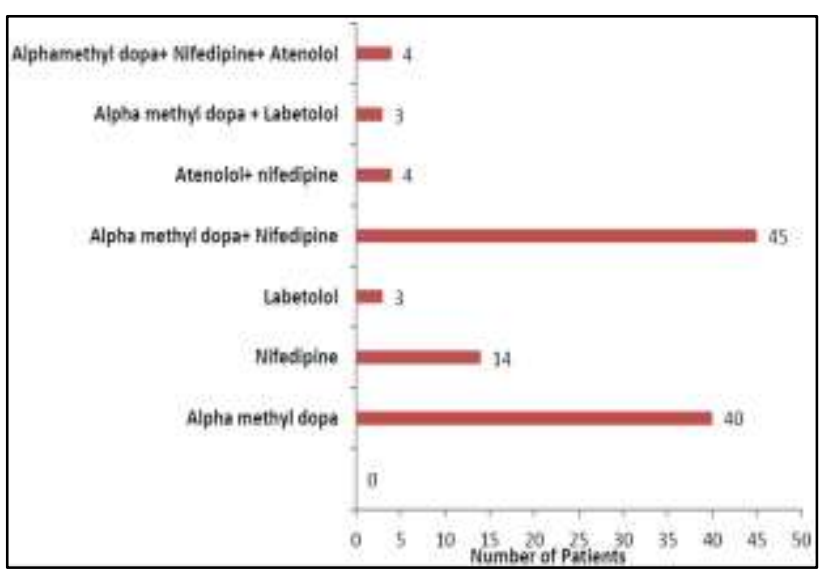

Figure 3: Pattern of antihypertensives prescribed.

\section{DISCUSSION}

In our study, majority of the hypertensive pregnant women were in primigravida and of mild to moderate degree of hypertension. In this study, most common drug used was alpha methyldopa followed by the combination of alpha methyldopa and nifedipine as specified in some guidelines. $^{8-10}$

The results were almost comparable with a study done in north India whereas in another south Indian study, calcium channel blocker nifedipine was the most commonly prescribed drug in pregnancy for the treatment of hypertension. ${ }^{5,11}$ According to National high blood pressure education program (NHBPEP), alpha methyl dopa was the most recommended safe antihypertensive drug in hypertensive pregnant women. ${ }^{1,9}$ Monotherapy was most favoured as most of them were having mild to moderate hypertension.

Only in uncontrolled condition, dual drug therapy or triple therapy was followed. This was more seen in hypertensive women with comorbid illness probably it can be attributed to polypharmacy consumption to treat multiple disorders. Neonatal deaths were noticed in patients with preeclampsia and severe eclampsia.

\section{CONCLUSION}

It was found in our study that antihypertensive prescribed was rational. Most of the prescriptions contain monotherapy with alpha methyl dopa, which is considered to be safest antihypertensive in pregnancy since several decades. Neonatal outcome can be improvised if the hypertension is identified at early weeks of pregnancy; and managed with fewer medication and life style modification.

\section{Funding: No funding sources}

Conflict of interest: None declared

Ethical approval: The study was approved by the Institutional Ethics Committee

\section{REFERENCES}

1. Zibaeenezhad MJ, Ghodsi M, Arab P, Gholzom N. The prevalence of hypertensive disorders of pregnancy in Shiraz, Southern Iran. Iranian Cardiovascular Research Journal. 2010;4(4):169-72.

2. Report of the National high blood pressure education program working group on high blood pressure in pregnancy. Am J Obstet Gynaecol. 2000;183:S1-S22.

3. Jabeen M, Yakoob MY, Imdad A, Bhutta AZ. Impact of interventions to prevent and manage preeclampsia and eclampsia on stillbirths. BMC Public Health. 2011;11(S6).

4. Hypertension in pregnancy (Report of the ACOG task force on hypertension in pregnancy). Obstetrics and Gynaecology. 2013;122(5).

5. Hooli TV, Santoshkumar J, Manjunath S, Vinodkumar CS. Drug utilization study of antihypertensives in obstetric practice in a tertiary care hospital. IJABPT. 2010;1(3):1006-10.

6. Caton AR, Bell EM, Druschel CM, Werler MM, Lin AE, Browne ML. Antihypertensive medication use during Pregnancy and the risk of cardiovascular malformation. Hypertension. 2009;54:63-70.

7. Sharma R, Khajuria R, Sharma P, Sadhotra P, Kapoor B, Kohli K, et al. Glaucoma therapy: prescribing pattern and cost analysis. JK Science. 2004;6(2):88-92.

8. JNC 7 express. The seventh report of the Joint National committee on prevention, detection, evaluation and treatment of high blood pressure. Available at http://www.nhlbi.nih.gov/guidelines/hypertension/ex press.pdf. Accessed 28 January 2016. 
9. Podymow T, August P. Update on the use of antihypertensive drugs in pregnancy. Hypertension 2008.

Available

\section{at} http://hyper.ahajournals.org/content/51/4/960.full.pdf +html. Accessed 04 February 2016.

10. Magee LA, Pels A, Helewa M, Rey E, Dedelszen PV. Diagnosis, evaluation and management of the hypertensive disorders of pregnancy: executive summary. J Obstet Gynaecol Can. 2014;36(5)416-34. 11. Pandya AS, Mistry VR, Chaudhari JS, Karelia BN, Shankar C, Hotchandani. Drug utilization study of antihypertensive drugs in pregnancy induced hypertension. Int J Res Med. 2013;2(2);26-9.

Cite this article as: Yamakanamardi S, Anuradha HV, Sujani BK, Shivamurthy MC. Analysis of prescribing pattern of antihypertensive drugs during pregnancy and neonatal outcome in a tertiary care centre. Int J Basic Clin Pharmacol 2016;5:718-21. 